\title{
Automatic high resolution measurement set-up for calibrating precise line scales
}

\author{
Klobucar, R..$^{\mathrm{a},{ }^{*}}$, Acko, B. ${ }^{\mathrm{a}}$ \\ ${ }^{a}$ Faculty of mechanical engineering, University of Maribor, Maribor, Slovenia
}

\begin{abstract}
A B S T R A C T
This paper presents a high resolution measurement set-up developed for calibrating precise line scales with measurement uncertainty of less than 0.1 $\mu \mathrm{m}$ over a total length of $500 \mathrm{~mm}$. The system integrates a numerically controlled multi-axis stage, a laser interferometer, and a vision system for detecting line position. The measurement and the analysis processes are completely automated in order to minimize manual labour during the calibration process, but also increase the calibration accuracy. Increasing calibration accuracy leads up to better quality of industrial measurements which is required by modern precision industry. When designing this set-up, special attention was paid to the alignment of the measurement object in the measurement direction, considering the focus of the camera. The aim of this alignment was to reduce Abbe errors in 2 axes to negligible level. In addition, all uncertainty contributions have been determined and evaluated by performing extended experiments in specific measurement conditions. These contributions are presented in the uncertainty budget. The metrological capabilities of the presented measurement set-up were verified by some practical test measurements. Selected results of these measurements are presented in the article. This set-up will primarily improve a standard base for calibration of optical measuring devices. The use of the optical standards in the industry is constantly growing. Indirect users of the results of this research will be all manufacturers of precise products such as automotive and other industries.
\end{abstract}

\section{ARTICLE INFO}

Keywords: Measurement

Line scales

High resolution measurements

Measurement uncertainty

*Corresponding author: rok.klobucar@um.si

(Klobucar, R.)

Article history:

Received 15 September 2016

Revised 27 February 2017

Accepted 1 March 2017

\section{References}

[1] Koops, R., Mares, A., Nieuwenkamp, J. (2010). A new standard for line-scale calibrations in the Netherlands, Mikroniek - Professional Journal on Precision Engineering, Vol. 50, No. 4, 5-12.

[2] Meli, F. (2013). Calibration of photomasks for optical coordinate metrology, Physikalisch-Technische Bundesanstalt (PTB), No. 8, 1-12, doi: 10.7795/810.20130620C.

[3] Kajima, M., Watanabe, T. Abe, M., Takatsuji, T. (2015). Calibrator for 2D grid plate using imaging coordinate measuring machine with laser interferometers, International Journal of Automation Technology, Vol. 9, No. 5, 541-545, doi: 10.20965/ijat.2015.p0541.

[4] Flügge, J., Köning, R., Weichert, Ch., Häßler-Grohne, W., Geckeler, R.D., Wiegmann, A., Schulz, M., Elster, C., Bosse, H. (2009). Development of a 1.5D reference comparator for position and straightness metrology on photomasks, In: SPIE Proceedings, Photomask Technology 2008, Vol. 7122, Monterey, CA, USA, doi: 10.1117/12.801251.

[5] Acko, B. (2012). Final report on EUROMET key comparison EUROMET.L-K7: Calibration of line scales, Metrologia, Vol. 49, doi: 10.1088/0026-1394/49/1A/04006.

[6] Lassila, A. (2012). MIKES fibre-coupled differential dynamic line scale interferometer, Measurement Science and Technology, Vol. 23, No. 9, doi: 10.1088/0957-0233/23/9/094011. 
[7] Leach, R. (2015). Abbe error/offset, In: Laperrière, L., Reinhart, G. (eds.), CIRP Encyclopaedia of Production Engineering, Springer, Berlin, Germany, 1-4, doi: 10.1007/978-3-642-35950-7_16793-1.

[8] Klobucar, R., Acko, B. (2016). Experimental evaluation of ball bar standard thermal properties by simulating real shop floor conditions, International Journal of Simulation Modelling, Vol. 15, No. 3, 511-521, doi: 10.2507/ ijsimm15(3)10.356.

[9] Družovec, M., Ačko, B., Godina, A., Welzer, T. (2009). Robust algorithm for determining line centre in video position measuring system, Optics and Lasers in Engineering, Vol. 47, No. 11, 1131-1138, doi: 10.1016/i. optlaseng.2009.06.017.

[10] Newport Corporation. Air bearing solution guide, from https://www.newport.com/g/air-bearing-solutionselection-guide, accessed December 2, 2016.

[11] Köchert, P., Flügge, J., Köning, R., Weichert, C., Guan, J. (2013). Redetermination of the abbe errors' uncertainty contributions at the nanometer comparator, In: Proceedings of the 9th International Conference on Measurement, Smolenice, Slovakia, 171-174.

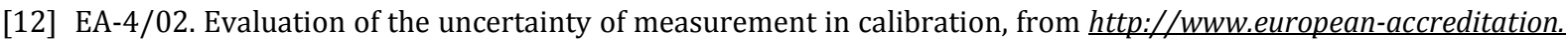
org/publication/ea-4-02-m-rev01-september-2013, accessed November 22, 2016.

[13] Acko, B., Brezovnik, S., Crepinsek Lipus, L., Klobucar, R. (2015). Verification of statistical calculations in interlaboratory comparisons by simulating input datasets, International Journal of Simulation Modelling, Vol. 14, No. 2, 227-237, doi: 10.2507/IJSIMM14(2)4.288.

[14] Acko, B., Sluban, B., Tasič, T., Brezovnik, S. (2014). Performance metrics for testing statistical calculations in interlaboratory comparisons, Advances in Production Engineering \& Management, Vol. 9, No. 1, 44-52, doi: 10.14743/apem2014.1.175. 
APEM
Advances in Production Engineering \& Management Letnik 12 | Številka 1 | Marec 2017 | Strani 88-96 https://doi.org/10.14743/apem2017.1.242
ISSN 1854-6250

Spletna stran: apem-journal.org Izvirni znanstveni članek

\title{
Avtomatizirani merilni sistem visoke ločljivosti za umerjanje preciznih črtnih meril
}

\author{
Klobucar, R. ${ }^{\mathrm{a},{ }^{*}}$, Acko, B. ${ }^{\mathrm{a}}$ \\ ${ }^{\mathrm{a}}$ Faculty of mechanical engineering, University of Maribor, Maribor, Slovenia
}

\begin{abstract}
POVZETEK
V članku je opisan merilni sistem visoke ločljivosti, ki smo ga razvili za umerjanje preciznih črtnih meril z merilno negotovostjo pod $0,1 \mu \mathrm{m}$ na dolžini 500 $\mathrm{mm}$. Sistem je sestavljen iz numerično vodenega večosnega merilnega stroja, laserskega interferometra in optičnega sistema za razpoznavanje pozicije črtice. Procesa merjenja in analize podatkov sta popolnoma avtomatizirana. Z avtomatizacijo smo minimizirali ročno delo med procesom umerjanja in povečali zanesljivost umerjanja. Povečana zanesljivost umerjanja omogoča višjo kakovost industrijskih meritev, ki je v skladu z zahtevami moderne precizne proizvodnje. Med snovanjem tega merilnega sistema smo posvetili posebno pozornost poravnavi objekta umerjanja z osjo merjenja ob upoštevanju fokusne razdalje merilnega mikroskopa s kamero. Cilj te poravnave je bilo zmanjšanje Abbejevega pogreška $\mathrm{v}$ dveh oseh na zanemarljivo raven. Poleg tega smo tudi ovrednotili vse prispevke k merilni negotovosti na osnovi obširnih eksperimentalnih meritev v specifičnih merilnih pogojih. Ti prispevki so prikazani v obliki preglednice, ki poleg prispevkov vključuje še izračunano standardno negotovost meritve. Meroslovne zmogljivosti predstavljenega merilnega sistema so bile potrjene s praktičnimi meritvami. Izbrani rezultati teh meritev so prikazani v članku. Ta merilni sistem bo predvsem izboljšal etalonsko bazo za umerjanje optičnih merilnih naprav. Ker je uporaba optičnih etalonov $\mathrm{v}$ industriji $\mathrm{v}$ nenehnem porastu, bodo posredni uporabniki rezultatov te raziskave številni proizvajalci preciznih proizvodov $\mathrm{v}$ avtomobilski in drugih vejah industrije.
\end{abstract}

PODATKI O ČLANKU

Ključne besede: Meritev

Črtna merila

Meritve z visoko ločljivostjo,

Merilna negotovost

*Kontaktna oseba: rok.klobucar@um.si (Klobucar, R.)

Zgodovina članka: Prejet 15. septembra 2016 Popravljen 27. februarja 2017 Sprejet 1. marca 2017 